\title{
Theorizing Regulatory Intermediaries: The RIT Model*
}

\author{
Kenneth W. Abbott, David Levi-Faur and Duncan Snidal
}

\section{September 182016}

\begin{abstract}
:
Regulation is typically conceived as a two-party relationship between a rule-maker or regulator $(\mathrm{R})$ and a rule-taker or target $(\mathrm{T})$. We set out an agenda for the study of regulation (and rules more broadly) as a three- (or more) party relationship -- with intermediaries (I) at the center of the analysis. Intermediaries play major and varied roles in regulation, from providing expertise and feedback to facilitating implementation, monitoring the behavior of regulatory targets and building communities of assurance and trust. After developing the basic RIT model, we discuss important extensions and variations. We then discuss the varieties of regulatory capture that appear where intermediaries are involved.
\end{abstract}




\section{Biographies:}

Kenneth W. Abbott is Jack E. Brown Professor of Law, Professor of Global Studies, and Senior Sustainability Scholar at Arizona State University. His research focuses on the interdisciplinary study of international institutions, international law and international relations.

David Levi-Faur is the head of the Federmann School of Public Policy and Government and member of the Department of Political Science at the Hebrew University of Jerusalem. He is a founding editor of Regulation \& Governance. He is currently working on the interaction between regulation and welfare state governance.

Duncan Snidal is a Professorial Fellow of International Relations at Nuffield College, University of Oxford. He is a founding editor of International Theory and studies the role of formal and informal institutions in promoting international cooperation.

Key words: intermediaries, rule-takers, rule-makers, regulation, regulatory governance, orchestration, capture

*Note: We are happy to acknowledge a grant from the Leonard Davis Institute for International Relations at the Hebrew University, which helped launch this project. Earlier versions of this paper were presented at a workshop at Hebrew University, and in meetings of the Society for Advancement of Socio-Economics, Chicago and London, and a meeting of the Regulatory Governance group at IBEI Barcelona. We thank the participants in those workshops, anonymous reviewers, and the contributors to this volume for their valuable inputs. 


\section{Introduction}

Regulation is typically conceived as a two-party relationship between a rule-maker or regulator (R) and a rule-taker or target $(\mathrm{T})$. This conception can be represented as

$$
\mathbf{R} \rightarrow \mathbf{T}
$$

where $\mathrm{R}$ is an actor with authority and capability to regulate the target $\mathrm{T}$, whose behavior it seeks to affect. In fact, however, both rule-makers and rule-takers often require various forms of external assistance and resources to accomplish their goals. To this end, they may engage with (or be engaged by) diverse intermediaries, which subsequently act on their behalf or in conjunction with them to achieve their regulatory goals. These intermediaries - their interests and functions, successes and failures - stand at the center of our conceptualization of regulatory governance as a three (or more)-party relationship, represented as

$$
\mathbf{R} \longrightarrow \mathbf{I} \longrightarrow \mathbf{T}
$$

Regulatory intermediaries can be private sector actors, such as for-profit certification companies, accounting firms or credit ratings agencies; civil society groups, such as NGOs; or governmental bodies, such as transgovernmental agency networks or international organizations. Even states can be intermediaries, for example, by promoting compliance by other states with a mandate of the UN Security Council. In principle, any actor - public or private, domestic or international - can act as a regulatory intermediary. ${ }^{1}$ Intermediation can be formal and an actor's singular function, but it can be also be informal and one of many roles an actor plays.

This paper analyzes the major and varied roles that intermediaries play in regulation, from providing expertise and feedback to facilitating implementation, monitoring the 
behavior of regulatory targets and building assurance and trust. The U.S. Food and Drug Administration (FDA) enlists independent bodies to accredit private auditors to monitor food imports, supplementing the limited number of agency inspectors (Lytton 2017). Private standards schemes such as the Marine Stewardship Council (MSC) and Fairtrade International (FLO) also rely on independent accreditors and auditors (Auld and Renckens 2017; Loconto 2017). Recent international human rights agreements require participating states to establish independent national bodies to promote implementation (Pegram 2017). The European Union (EU) relies on transgovernmental networks of national agencies, as well as “networked agencies” composed of national bodies, to implement EU rules consistently and provide expert feedback (Levi-Faur 2011b; Blauberger \& Rittberger, 2015).

Regulatory intermediaries, and intermediation itself, are often contested and controversial. During the recent financial crisis, private credit ratings agencies - authorized to assess the risk of financial instruments for regulatory purposes such as bank capital requirements - made exorbitant profits and were widely seen as both having favored private interests and having failed spectacularly (Kruck 2017). The tragic 2012 factory fire in Karachi created a crisis for private regulation when it was revealed that accredited private auditors had recently certified the factory (Levi-Faur and Starobin 2014; Fransen and Conzelmann 2015). In both cases, issues of effectiveness, legitimacy, accountability, transparency and capture were raised vis-à-vis the intermediaries and the institutional designs (regimes) in which they operated.

The conceptualization and study of intermediaries is essential for an understanding of regulatory governance (Shearing \& Stenning 1987; Scott 2004; Black 2008; Levi-Faur 2011a; Kosta, 2016). We consider the diverse roles and functions of regulatory intermediaries, their strategies and governance technologies, and their impacts on regulatory 
outcomes, including both their "brighter and darker sides” (van der Heijden 2017). Thus, this paper contributes directly to a number of growing literatures, including those on certification and codes as a regulatory technology (Meidinger 2003; Bartley 2011; Starobin \& Weinthal 2010; O'Rourke 2003; Loconto and Busch 2010; Toffel et al. 2015); global regulatory chains (Gereffi et al. 2001; Nadvi 2008; Nadvi \& Raj-Reichart 2015; van der Ven 2015); corporate social responsibility (Bernstein and Cashore 2007); and meta-regulation (Coglianese and Lazer 2003; Gilad 2010).

Focusing attention on intermediaries expands the scope of regulatory analysis beyond rule-makers and rule-takers to include other key agents. It emphasizes that regulation often operates indirectly via chains of intermediation, and it highlights ways in which regulators and targets can expand their capacities by selecting, engaging and even creating intermediaries. Attention to intermediaries also takes regulatory analysis beyond the role of the state ${ }^{2}$ and the realm of legalized rules, on one hand, and beyond the national-international divide, on the other. It allows us to take account of the diverse private and hybrid publicprivate actors and complex regulatory systems. Questions of special importance include the relative effectiveness of different two-party and three-party regulatory arrangements, the influence of intermediaries on regulatory interactions, who wins and who loses from intermediation, and, of course, the power relations among regulatory actors, including possibilities for capture.

In this paper, we develop a general model of the role of intermediaries in regulatory governance. We concentrate primarily on intermediaries that figure in the implementation, monitoring and enforcement of rules - that is, intermediaries whose roles come into play once a regulation has been adopted. We include intermediaries that, in a dynamic sense, 
facilitate the ex post assessment and revision of rules and the development of communities of practice around them.

Our focus on regulatory intermediaries broadens the analysis of regulation in at least three ways. First, we show that regulation is not just about regulatory agencies or even the state. It also involves private actors as rule-makers, intermediaries and targets, often in complex private governance regimes (Büthe 2010; Vogel 2008, 2010; Koenig-Archibugi and Macdonald 2013; Potoski \& Prakash 2011). Second, we address not only domestic but also international and transnational regulation and the wide variety of actors that act as intermediaries. Our framework thus resonates with the "regulatory capitalism," "regulatory governance” and orchestration approaches to politics and policy (Levi-Faur 2005, 2011a; Ayres and Braithwaite 1992; Braithwaite 2008; Abbott, Genschel, Snidal and Zangl 2015; Guardiancich \& Guidi 2016). Third, we consider not only formal regulatory arrangements, but also informal arrangements that substitute for or supplement formal regulation. Finally, our analysis applies across a wide range of substantive areas - from food to finance to fisheries and beyond.

\section{The RIT Model}

We frame the RIT model largely in rationalist terms, focusing on actors and the incentives they face, but the model can accommodate sociological or constructivist considerations and non-material goals as well.

\subsection{The Basic Three-Party Model}

We begin by assuming a unidirectional flow of intention and action, in which a regulator (public or private; domestic, international or transnational) adopts regulations and chooses intermediaries in order to change the behavior of particular targets. The arrows in the $\mathbf{R} \rightarrow \mathbf{T}$ 
and $\mathbf{R} \rightarrow \mathbf{I} \rightarrow \mathbf{T}$ notations represent this unidirectional flow. The unidirectional assumption corresponds to the traditional, hierarchical view of regulation depicted in principal-agent models, where regulation is prescriptive and compliance is based primarily on deterrence and sanctions. From this baseline, however, we will see that both targets and intermediaries may reverse the directional arrows in pursuit of their goals. Feedback and other forms of intermediary involvement can be highly beneficial, but they can also create significant problems for regulation, including capture.

We focus on regulation that takes the form of rules. Those rules could be "hard," as in highly legalized domestic regulation; they could instead be "soft," as in much international regulation, where legalization is more limited (Abbott and Snidal 2000). In fact, regulation at both levels is frequently a mix of hard and soft rules, in part because it is typically impossible to write a complete set of hard rules without softer supporting arrangements regarding implementation. Where non-state actors fill the role of regulator, the rules they prescribe, often described as “standards,” are typically “voluntary,” not legally binding. They may, however, share other properties of legal rules (e.g., precision) and may be backed by significant incentives for targets to adhere and comply.

An example of a "hard” regulation is a legally-binding environmental rule, adopted by a national regulatory agency, to govern the production processes of business firms. The rule may impose precise requirements such as maximum emission levels, or may entail more general requirements, such as adoption of an environmental management plan, that may require interpretation by courts. An example of “soft” regulation is an environmental performance standard promulgated by an NGO or multi-stakeholder organization such as MSC, which lacks authority to adopt legally-binding rules, but promotes voluntary adherence 
and compliance by targets. Governmental bodies also use soft regulation at both the domestic and international levels.

In analyzing both types of regulation, the two-party $\mathbf{R} \rightarrow \mathbf{T}$ model of regulation is too simple in many respects. It excludes important actors, and therefore limits our understanding of complex processes such as the capture of regulators or intermediaries. The two-party model also makes strong assumptions regarding the regulator's capacities to formulate, implement and enforce regulatory policies. Of particular concern are the implicit asumptions that $\mathrm{R}$ has direct access to $\mathrm{T}$, direct means of influence that can effectively change T's behavior, and direct means to gather information on compliance and the impact of the rules. In many circumstances, regulators lack direct access to their targets, means of influence or other capabilities necessary to regulate them, and/or sufficient channels for information gathering. A regulator suffering from these shortcomings will often seek to overcome them by working through a third party, which we label the "intermediary," designated I in the $\mathbf{R} \rightarrow \mathbf{I} \rightarrow \mathbf{T}$ formulation.

We have generalized the RIT model from the model of orchestration (O-I-T), which depicts how an orchestrator (which may be a regulator) uses "soft” techniques to engage intermediaries that utilize their own capabilities to shape the behavior of targets. ${ }^{3}$ But a similar situation often underlies principal-agent (P-A) or delegation models of regulation, where the principal delegates authority to an agent to affect the behavior of a target. In both cases, RIT presents regulation as indirect, operating through an intermediary. The P-A model is normally seen as involving a direct relationship, because it concentrates on interactions between the principal and the agent (implicitly treating the agent's ability to manage the target as unproblematic). By contrast, the RIT model encompasses the full range of 
relationships between the principal and the target as mediated by the agent (i.e., P-A-T). Our focus, however, is the role of the intermediary, with respect to both regulator and target.

Returning to our examples of regulation, hard RIT regulation might involve a national regulatory agency (such as the FDA) adopting legally-binding production rules, while using external (private) intermediaries, as well as its own employees, to monitor compliance with them. Soft RIT regulation might involve a private standard-setting body such as the MSC or FLO utilizing independent auditors to certify compliance by targets. The RIT model thus helps us better understand both intra-governmental and extra-governmental relationships within regulatory regimes. In both examples, the intermediary is chosen because it has specialized expertise and other capacities that allow it to interpret the rules, supervise their implementation and monitor compliance more effectively than can the regulator itself.

\subsection{Intermediaries and their Properties}

We can define an intermediary in the basic RIT model as any actor that acts directly or indirectly in conjunction with a regulator to affect the behavior of a target. The intermediary is a go-between, whose presence necessarily makes some aspects of regulation indirect, as the intermediary stands between the regulator and its target. Its role can be formal or informal; its participation can be driven by functional or power considerations; and it can serve public or private interests. The inclusion of one or more intermediaries in a regulatory regime represents the kind of move towards more complex forms of governance that is captured by the notions of regulatory governance and decentred governance (Levi-Faur 2011a; Black 2008). Note again that our interest in regulation leads us to focus only on regulatory intermediaries; we exclude a wide variety of intermediaries, such as banks, brokers and matchmakers, which operate in non-regulatory contexts. While much of our 
analysis may apply to such cases, we tailor it here to the specific case of regulatory intermediaries.

The R-I and I-T relationships may both be explicit or tacit. The regulator may formally engage the services of the intermediary, as FLO contracts with the independent organization FLO-CERT to conduct certification audits. The target may also formally engage an intermediary, such as an external auditor, to meet a regulator's requirements. In other cases, there may be no formal arrangement at all - as when a regulator crafts a rule in anticipation that a third-party intermediary will respond in certain ways vis-à-vis the target, but without directly engaging that party. For example, a regulator without the ability to monitor compliance directly might adopt a rule knowing that NGOs will independently monitor target behavior. Similarly, a regulator might require targets to make certain disclosures, knowing that these will empower and provoke activists to pressure the targets to comply with regulatory rules. A regulator might also adopt a rule anticipating that other organizations will incorporate it into their own standards (Marx and Wouters 2017). Between the extremes of formal and tacit relationships, a regulator may orchestrate independent organizations, enlisting and supporting them to monitor and pressure targets to comply (De Silva 2017).

The goals of intermediaries vary widely. Private sector intermediaries such as auditing firms or credit ratings agencies need have no concern for the issue at hand, acting primarily for payment; some may share the interests of private sector targets, attempting to turn regulation to their benefit. NGOs and other civil society intermediaries may share the social values of the regulator (or even go beyond them) and act to help achieve them. Most intermediaries are organizations, so their organizational missions, interests and cultures also shape their willingness and ability to participate as intermediaries. Some intermediaries may have strong substantive or organizational interests in shaping the regulatory rules themselves. 
They may join other interest groups in lobbying at the rule adoption stage; rule-makers may also seek their expertise. Here we emphasize the ability of intermediaries to provide feedback to the regulator at later stages, based on their activities and experience.

These diverse goals make particular actors more or less suitable as intermediaries in specific situations; they may also produce conflicts of interests between regulators, intermediaries and targets that make regulation difficult. Yet the "individual" interests of potential intermediaries may be mediated or exacerbated by cooperation and competition among them, by their bargaining power vis-à-vis regulators and targets (Mattli and Seddon 2015), and by opportunities to collaborate with regulators or targets. To understand regulatory outcomes, such interactions need to be taken into account.

The principal reason for regulators to incorporate intermediaries into the regulatory process is that intermediaries possess capacities relevant to regulation that regulators themselves lack, or that intermediaries can provide more effectively or at lower cost. Shortly we will discuss these capacities in terms of what intermediaries actually do - that is, the functions and roles they perform. As a prelude to that discussion, it is useful to enumerate four broad categories of capacities that intermediaries bring to regulatory governance: ${ }^{4}$

- Operational capacity: Regulators often turn to intermediaries to carry out concrete activities in the field for which the regulators lack capacity, or that they would find too expensive. Operational capacities include the ability to deliver services, provide advice and support to facilitate targets’ implementation, monitor target behavior, and sometimes enforce regulations. A capacity of particular importance is “access” intermediaries are often better able to make contact with certain targets than are regulators, enhancing their ability to perform other tasks. 
- Expertise: Although it could be viewed as a subcategory of operational capacity, expertise is such an important capacity that it should be distinguished. Intermediaries are often brought in because they possess specialized knowledge about regulatory norms and how to implement them. This includes knowledge of target behavior - from management and accounting procedures to production and distribution practices - so that compliance can best be assisted, monitored and enforced - as well as knowledge of local conditions, so that regulations can best be adapted.

- Independence: In many regulatory situations it is important for the intermediary to be independent from the regulator and/or the target in order to be effective. For example, independence from the regulator is important for intermediaries tasked with assessing the impact of rules, and for courts or other dispute resolution bodies charged with interpreting or determining the validity of rules under general legal norms. Independence from the target is essential for intermediaries to act as credible monitors of compliance. Independence has multiple dimensions and comes in degrees. For example, an intermediary may have formal independence, but that may be impaired if it depends on the target for resources, or even for its designation as intermediary (Pegram 2017).

- Legitimacy: Targets, beneficiaries (Koenig-Archibugi and Macdonald 2017) and other audiences may view an intermediary as having greater legitimacy in performing some activity than the regulator itself. Independence and expertise are both important sources of input legitimacy; operational capacity may be relevant to output legitimacy. In addition, the membership, structures and procedures of intermediaries may increase legitimacy; for example, some intermediaries may be seen as incorporating and consulting a wider range of stakeholders than the regulator. 
These categories are neither exhaustive nor exclusive. Nonetheless, they provide a useful starting point in considering why a regulator might engage intermediaries.

Most of these capacities must be assessed relative to a specific context or situation: an intermediary might have high capacity in one setting but not in another. Capacities such as access to targets, expertise about a problem or target behavior, independence from the regulator, and legitimacy almost all depend on the specific regulatory activity at stake. Similarly, the same intermediary may have different capacities vis-à-vis different regulators, targets or regulatory issues.

Finally, regulators can only utilize intermediaries if appropriate actors with the necessary capacities are available. Intermediaries are frequently pre-existing rather than created anew. A regulator may, for example, search the landscape of actors and identify NGOs active on an issue; it can then activate them as intermediaries or orchestrate their participation in regulatory governance. In other cases, intermediaries may present themselves; firms with expertise in auditing and certification, such as SGS or Bureau Veritas (Galland 2017), often actively seek to assist regulators in return for payment.

In other cases, however, no appropriate intermediary may exist. Yet this does not necessarily pose an insuperable barrier to intermediation, as the regulator may be able to create suitable intermediaries for the task at hand. A national regulatory agency may create an expert body to facilitate implementation by targets; a supranational body such as the EU may create a network of national regulators to assist it in translating rules to national contexts; an international organization such as the UN Environment Program (UNEP) may help to create a multi-stakeholder organization (such as the Global Reporting Initiative) to adopt and implement voluntary regulatory standards (Abbott and Snidal 2010). 
Often the role of intermediary depends on acceptance and perhaps authorization or empowerment by the regulator. To be sure, some intermediaries - such as NGOs that monitor target behavior - operate independently of the regulator, and jealously guard their independence. But even for intermediaries with independent capabilities and roles, working with a regulator typically magnifies their impact. For example, credit ratings agencies have access and expert authority independent of the state; they may even have independent moral authority because of their role as neutral arbiters. Public acceptance of their activities may be enough to make them effective gatekeepers in credit markets (Kraakman 1986; Partnoy 2007). Nonetheless, working with a regulator confers state endorsement, and may even give their decisions the force of law (Kruck 2017). In other cases, the regulator actually creates the intermediaries' roles - as by requiring audits by independent monitors to certify target performance, or accreditation of monitors by independent bodies (Auld and Renckens 2017; Loconto 2017; Lytton 2017). The resources and authority the regulator provides may give it some degree of control over intermediaries, and may protect them from capture by targets but the need for intermediary independence may constrain such control (Maggetti et al. 2017).

\section{The Regulatory Roles of Intermediaries}

Intermediaries perform a variety of functions linked to their roles in regulatory governance. They can be judges, facilitators, community builders, monitors and so forth. Intermediary organizations also can perform multiple roles, at the same time or over time. Here we discuss these roles/functions in terms of a few broad categories. We base these on the five stages of the regulatory process presented in Abbott and Snidal (2009): AgendaSetting, Negotiation, Implementation, Monitoring and Enforcement (ANIME). However, we begin with implementation, because of our general focus on the period after a regulator has 
adopted a rule. We also provide for post-adoption feedback, which brings agenda-setting and negotiation back into play.

\subsection{Implementation}

Although targets must ultimately implement regulations, intermediaries facilitate many aspects of implementation. First, they interpret or clarify regulatory rules, elaborate them, and adapt them for the circumstances of particular firms, industries, states or other targets. This may entail "translating” regulations into practical forms, as by creating guides or elaborating best practices. We hypothesize, then, that intermediaries will be more often utilized to perform this function where regulatory rules are broad or ambiguous or where they apply to diverse sectors or other target groups. Second, intermediaries can provide training and advice on implementation, including technical assistance, and may even provide some material support, e.g., for developing country firms or small-medium enterprises. Third, intermediaries can evaluate the costs and impacts of alternative means of implementation, helping targets and regulators to pursue the most efficient ways of achieving regulatory goals.

Implementation draws on a range of intermediary capacities. Expertise and operational capacities, including access to targets, are of paramount importance; independence may be central to certain regulatory tasks, such as evaluation.

\subsection{Monitoring and Enforcement}

For regulation to be effective, the target's performance must typically be monitored, through "police patrol” or "fire alarm" procedures; the rule must then be enforced if performance deviates from that prescribed. ${ }^{5}$ Intermediaries are valuable as monitors when they possess the necessary expertise and operational capacity, including access to targets, as well as sufficient independence to ensure credibility. Intermediaries also play important roles in activities that lie between monitoring and enforcement, such as dispute resolution and rule 
interpretation. Intermediaries are sometimes important as enforcers for privatized forms of domestic regulation, and even more so for international and private regulation, where regulators' enforcement authority is more limited. The actions of regulatory intermediaries such as public disclosure of non-compliance or revoking authorization to use a product label - may generate substantial pressure to comply, effectively hardening otherwise soft regulation.

These roles are often combined in a single intermediary that monitors and evaluates target behavior and enforces rules. For example, third-party certifiers may monitor target behavior against established rules, provide guidance for how to bring behavior into compliance, and enforce the rules through positive incentives - such as the market benefits of product labels - or negative sanctions, such as adverse publicity. Indeed, their activities can go far beyond these simple carrots and sticks to include developing communities of compliance; promoting dialogue among targets, regulators and others; and changing the organizational culture of targets. In the FLO system, for example, the intermediary FLOCERT conducts certification and verification audits of targets, interprets FLO standards, and resolves disputes related to product labeling; it also facilitates implementation through guidance and consulting and provides formal feedback to FLO and targets (Loconto 2017).

As noted above, an important issue in this context is how the intermediary is financed, especially who pays for monitoring and enforcement. If targets pay for audits and other forms of monitoring, as they do in many private regulatory systems (including FLO) and in some privatized governmental regulation (van der Heijden 2017), that raises questions of credibility, which can sometimes be offset by the monitor's reputation for independence or by institutional arrangements such as accreditation. If regulators or other parties pay for such 
services, that may provide a point of control for them, undermining intermediary independence.

\subsection{Agenda-setting and Negotiation: Dynamic Rule Development}

The basic $\mathbf{R} \rightarrow \mathbf{I} \rightarrow \mathbf{T}$ model assumes that the regulator alone promulgates the relevant rules (presumably after input from concerned interests), so it effectively treats those rules as exogenous to the actions of intermediaries and as static. In fact, however, regulations rarely remain unchanged, and feedback from intermediaries (as well as from targets, beneficiaries and other evaluative audiences) can contribute importantly to their evolution over time (Auld and Renckens 2017). While this dynamic view of the RIT relationship might be viewed as an extension of the basic model, it is so central to the roles of regulatory intermediaries that we include it here under the headings of agenda-setting and negotiation, which are typically seen as the initial stages of the regulatory process.

Intermediaries are often important in the development of rules over time. Feedback from intermediaries may be based on their own experience with the interpretation and implementation of rules: they can provide first-hand information on areas of ambiguity, problems of maladaptation to local conditions, difficulties of implementation and burdensome demands, barriers to effective monitoring, more efficient alternatives and similar matters, indicating how rules might be revised, rescinded or expanded. Where intermediaries are close to targets, they can pass on the targets' views, suggesting how rules might be amended to lessen regulatory burdens while achieving regulatory goals; they can also help build communities of compliance among targets and other stakeholders in society. Perhaps idealistically, intermediaries can be facilitators and mediators, enhancing trust and strengthening "regulatory dialogues" between regulators and targets, and helping them to 
collaborate in improving the effectiveness of regulation while lowering its costs and adverse implications.

Strong intermediary feedback may be unanticipated (and even unwanted) by the regulator, but smart regulators will anticipate, encourage and plan for it. For example, the EU uses national agencies to help it formulate and implement its rules, and UN organizations accredit certain NGOs as observers to meetings and as on-going partners for similar reasons. Intermediaries, though, may see this as an opportunity to shape regulatory rules to meet their own goals, and even to capture regulatory authority.

\subsection{Institutionalizing the Role of Intermediaries}

While our model of intermediation is actor-centered, intermediaries do not operate in a vacuum. Like other actors, they are embedded in institutional environments that shape their roles, opportunities for action, capabilities and legitimacy (North 1990; DiMaggio and Powell 1991; Hall \& Taylor 1996). If successful, moreover, regulatory innovations, by design or by trial and error, are institutionalized, become norms, and come to be taken for granted. Intermediation practices and architectures too can be institutionalized, changing the architecture and balance of power within a regulatory regime. Institutions diffuse intermediation practices and architectures (by emulation, learning, coercion or incentives) and localize them for use by particular actors. In other words, the successful operation of intermediaries requires institutionalization and localization (Czarniawska-Joerges and Sevón 1996). Institutional analysis also allows for path dependency as an explanation for the structure and purposes of regulatory regimes and the power and autonomy of intermediaries within them (Streeck and Thelen 2005; Kruck 2017). 


\section{Extensions and Variations of the RIT Model}

So far, we have presented the RIT model in its simplest form, and then extended its static form to a dynamic version by considering feedback from targets to regulators, both directly and through intermediaries, and from intermediaries. This section discusses further elaborations of the model.

\subsection{Regulatory chains}

A regulatory system need not include only a single regulator or intermediary; such systems are frequently concatenated, with actors linked together in chains. The degree of support from political principals - such as legislatures or ministries - influences the regulator's need for intermediaries and its ability to control them (Maggetti et al. 2017). Among regulators, legislatures frequently delegate broad rule-making authority to administrative agencies. Courts and quasi-judicial bodies, likewise, may be granted such extensive authority to interpret broad constitutional, statutory or treaty provisions that they become, at least in part, regulators in their own right (De Silva 2017). ${ }^{6}$ Even where an intermediary’s main role is to assist in implementation, it may be required to interpret, translate and adapt rules to such a degree that - intentionally or not -it functions as a secondary regulator (Auld and Renckens 2017). And meta-regulators such as the Global Food Safety Initiative set standards for private regulatory schemes (Havinga and Verbruggen 2017).

Regulatory systems often include chains of intermediaries. An important example is the separation between auditors, building inspectors and similar actors, which monitor target compliance, and accreditation bodies, which assess the competency of auditors. Such chains are common in public (Lytton 2017), private (Loconto 2017) and privatized (van der Heijden 2017) regulation. Risking an infinite regress, accreditation bodies may themselves be 
required to receive accreditation from a higher authority. Often the regulator initiates this chain of relationships: $\mathbf{R} \rightarrow \mathbf{I}_{\mathbf{1}}-\mathbf{I}_{\mathbf{2}}-\mathbf{I}_{\mathbf{3}} \rightarrow \mathbf{T}$. In other cases, an intermediary may empower sub-intermediaries: $\mathbf{R} \rightarrow \mathbf{I}_{1} \rightarrow \mathbf{I}_{2} \rightarrow \mathbf{T}$ (De Silva 2017). For certain purposes, for example, it will be important to focus not only on the organization with overall responsibility to facilitate implementation or monitor compliance, but also on how individual employees, departments or subsidiary companies carry out those activities (Auld and Renckens 2017; Galland 2017; Lytton 2017).

Many regulatory systems include chains of targets. Typically, private standards address targets at the consumer-facing end of the supply chain, such as retailers. But these firms are often required to impose those standards on their suppliers, even requiring suppliers to obtain certification from independent auditors.

Finally, in a world of legal and regulatory pluralism (Berman 2012; Scott 2001), intermediaries often operate in parallel, while on a larger scale multiple regulatory chains operate in parallel within a regulatory regime. It is not uncommon for business firms (e.g., food producers) to be the target of multiple national regulatory systems, sub-national regulatory systems, industry self-regulatory systems, and private standards systems - each with its own chain of secondary regulators and intermediaries. The same organizations may even play similar intermediary roles across multiple regulatory systems - perhaps with homogenizing effects.

\subsection{Multiple roles and ambiguous boundaries}

The same actor may perform multiple functions within a single role in the regulatory process - as when an intermediary serves as facilitator, monitor and enforcer of target compliance. Even more important, while the RIT model treats the three main actors as clearly defined and distinct, these roles are not always clear-cut, as when intermediaries also perform 
regulatory functions or are the targets of regulations (Havinga and Verbruggen 2017). While the distinctions between actors may blur in practice, however, clarity in the theoretical model is useful for understanding the overall relationships.

We have already noted that intermediaries may operate as secondary regulators, when they are granted significant authority to make, interpret and adapt rules, or when they incorporate other regulators' rules into their own standards. Intermediaries may also overlap regulators more directly. In multi-stakeholder bodies such as the Forest Stewardship Council (FSC), for example, certification bodies participate as members in framing and adopting rules.

The intermediary and target may also overlap in diverse ways. For example, the intermediary may be an industry association; as such, it is more or less coextensive in membership with the target group, although regulatory activity may be focused on particular actors within that group, as in “responsive regulation” (Ayres and Braithwaite 1992). An industry association could be viewed as "belonging" to the targets, or as identical to them. It may, however, have somewhat different interests (e.g., acting for the industry, not for any individual firm) and develop different capacities, including some autonomy from its members $\left(\mathbf{R} \rightarrow \mathbf{T}^{*} \rightarrow \mathbf{T}\right)$. In other cases the intermediary could be a subset (t) of the target group ( $\mathbf{R}$ $\rightarrow \mathbf{t} \rightarrow \mathbf{T}$ where $\mathrm{t} \epsilon \mathrm{T}$ ). This approach resembles co-optation, enlisting a key element of the target population to pursue a regulatory agenda vis-à-vis the entire population (Selznick 1949). Where the intermediary is a multi-stakeholder organization, such as the FSC, its members will usually include targets. Some intermediaries (and regulators) follow a strategy of “embedding” targets deeply in their operations, facilitating learning and continuous improvement (Marx and Wouters 2017). 
In similar ways, regulators may overlap with targets. In a self-regulatory system such as the chemical industry’s Responsible Care program, an industry association is the regulator, with its own members its targets. Such a regulator may still employ diverse intermediaries, such as independent monitors. In a multi-stakeholder organization such as the FSC, the regulator normally includes targets in its governance structure. The extent to which these overlaps influence the quality of regulation - favorably or unfavorably - depends on both formal structures and informal relationships, and must be assessed through careful contextual analysis.

\subsection{A Dynamic RIT Model}

In a three-party regulatory system, feedback flows in multiple channels. Targets provide feedback directly to regulators; intermediaries provide feedback based on their own experiences; and intermediaries receive information and advice from targets and pass those on to regulators. These connections introduce a more dynamic model of regulation, which can be represented as

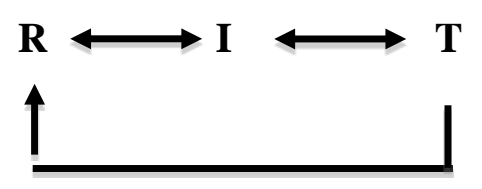

with the reverse arrows representing feedback. When the target provides feedback directly to the regulator, the sequence can be expressed R-I-T-R; when it provides feedback through an intermediary, as R-I-T-I-R. In the latter sequence, the intermediary may evaluate and filter T’s feedback, making it more useful to $\mathrm{R}$ while also insulating $\mathrm{R}$ from direct pressure by $\mathrm{T}$. This need not reduce the effectiveness of T's feedback; it may enhance it if I's independence gives greater credence and legitimacy to T’s message. But it also provides an opportunity for 
I to modify or add to T’s feedback in its own interest. As the cycle of feedback and rule revision continues, these sequences become iterative and increasingly lengthy.

Feedback processes like these are essential to understanding the development of regulation over time; neither principal-agent nor orchestration models typically pay sufficient attention to them. Of course, including all forms of feedback over long time periods can lead to overly complicated analyses. For that reason we stick with the simplest model (RIT), bringing in such complications only when needed to gain additional insights.

\subsection{Beneficiaries as Intermediaries and Targets}

A particularly important extension is considering the beneficiaries of regulation within the RIT model (Koenig-Archibugi and Macdonald 2017). Beneficiaries are always relevant to regulation. The analytical question is whether they should be treated as active participants in the RIT process; the normative question is whether including them (formally or informally) improves the quality of regulation. The RIT model can help clarify these relationships, bringing in beneficiaries as more than just passive actors where appropriate.

Beneficiaries figure in regulatory processes in several roles.

- In some cases, as when regulation solves collective action problems, the beneficiaries may actually be the targets; here they are already included in the RIT model, but their relationship can be specified more precisely $(\mathbf{R} \rightarrow \mathbf{I} \rightarrow \mathbf{B}){ }^{7}$

- More commonly, beneficiaries or their representatives act as intermediaries $(\mathbf{R} \rightarrow$ $\mathbf{B} \rightarrow \mathbf{T}$ ). Beneficiaries are likely to play especially active roles in monitoring (typically through fire-alarm mechanisms), if they have the capacities to do so, and in providing feedback on the effectiveness of regulation. For example, private regulatory schemes such as the Worker Rights Consortium and Fair Labor 
Association, and certification intermediaries such as FLO-CERT, rely on beneficiary complaints, and so can reduce their investment in costly police patrol monitoring. Under the Convention on the Rights of Persons with Disabilities, disabled persons’ organizations must participate in national mechanisms for rule promotion and monitoring (Pegram 2017).

- In multi-stakeholder regulation, beneficiaries may participate as part of the regulator (e.g., organizations of certified producers sit on the FLO board) or an intermediary (e.g., consumer beneficiaries sit on Participatory Guarantee System boards that certify compliance with IFOAM private organic standards, Loconto 2017). Independent intermediaries may also mobilize beneficiaries (i.e., solving their collective action problem) to bring pressure to bear on targets or regulators.

Beneficiaries are also significant at the dynamic stages of agenda-setting and rule reformulation. The regulator may simply consider their interests as a rationale for regulation, or they may actively advocate for regulation. Beneficiaries are thus of concern for both normative and positive reasons. When the regulator is accountable to beneficiaries (e.g., as political regulators are to voters), they can reward or punish it for its actions ( $\mathbf{R} \rightarrow \mathbf{I} \rightarrow \mathbf{T} \rightarrow$ $\mathbf{B} \rightarrow \mathbf{R})$.

\section{Failures of Intermediation: Capture}

Capture is an important issue in regulatory policy, and a major source of regulatory failure. The RIT model opens up new perspectives on capture, and on related regulatory failures, by addressing the interactions of all the actors in a regulatory system. We define capture broadly as the domination of one actor by another, restricting the autonomy of the captured actor in performing its regulatory functions (cf. Carpenter and Moss 2013). Whereas classical capture focuses on capture of the regulator by the target, the RIT model allows us to 
consider additional channels and subjects of capture. Table 1 summarizes four forms of capture in which intermediaries are prominently involved.

\begin{tabular}{|c|c|}
\hline Form of Capture & Regulatory Failure \\
\hline $\begin{array}{c}\text { Classical Regulatory Capture } \\
\text { T captures R }\end{array}$ & $\begin{array}{c}\text { Impedes regulation in public interest, but } \\
\text { intermediary may inhibit capture }\end{array}$ \\
\hline $\begin{array}{c}\text { Capture of Intermediary } \\
\text { T captures I }\end{array}$ & $\begin{array}{c}\text { Intermediary influences regulator, or modifies own } \\
\text { practices, to favor target }\end{array}$ \\
\hline Intermediary Captures Regulator & form of regulation \\
\hline I captures R & $\begin{array}{r}\text { Intermediary promotes its services, influences } \\
\text { Regulator Captures Intermediary } \\
\text { R captures I }\end{array}$ \\
\hline
\end{tabular}

Table 1: Forms of capture in RIT model

\subsection{Classical Regulatory Capture}

Classical capture occurs when the target dominates the regulator. A captured regulator loses its independence from the target, and is therefore diverted from pursuing regulation in the public interest. The target may also proactively persuade a regulator to adopt rules that benefit it ( $\mathbf{T} \rightarrow \mathbf{R})$. For example, firms often lobby regulators to limit competition - as when sports team owners seek anti-trust exemptions or stores lobby for laws restricting hours of operation (Stigler 1971). More dynamically, the regulator may initially establish a rule that furthers public policy goals, but the rule creates incentives for the target to penetrate or influence the regulator to mute the regulation's impact or, in the extreme case, to modify it to serve the target's (not the beneficiaries’ or the public’s) interests (Bernstein 1955; Carpenter and Moss 2013). 
While intermediaries might appear irrelevant in this setting, their involvement can inhibit capture. If a regulator engages third parties to act within the regulatory process - or even if their involvement is tacit - intermediaries can provide checks on capture by monitoring the behavior of targets and regulators, acting as whistle-blowers, and holding regulators and targets accountable, e.g., through public disclosure of misconduct. Intermediaries are most likely to play these roles when they are motivated by the regulatory goals themselves, as is frequently the case for beneficiaries.

\subsection{Capture of the Intermediary}

In other cases, intermediaries may provide not obstacles to capture by targets, but means for it to occur. Targets often lobby for the inclusion of intermediaries to perform tasks such as interpreting the rules, assisting in implementation, or monitoring. This could be a sincere effort to increase regulatory efficiency by expanding expertise and other capacities, while reducing compliance costs. For example, if a regulator lacks sufficient monitoring capacity to accurately differentiate complying from non-complying firms (Ayres and Braithwaite 1992), it may be forced to apply uniform regulations to all targets. By employing intermediaries with greater monitoring capacity, in contrast, the regulator can adopt more nuanced rules, reducing costs for itself and for complying firms.

Alternatively, however, targets may use intermediaries as a pathway to capture. Intermediation provides two channels for capture. First, the target may use the intermediary to capture the regulator, influencing the intermediary to recommend changes in the rules that favor the target $(\mathbf{R} \rightarrow \mathbf{I} \rightarrow \mathbf{T} \rightarrow \mathbf{I} \rightarrow \mathbf{R})$. Second, the target may capture the intermediary itself, influencing it to interpret or implement existing rules in ways that favor the target. Reliance on an intermediary reduces the cost of capture if the target only has to capture the weaker link (R or I) in the regulatory chain. Whether capture is likely, however, also depends 
on the "capture potential” of the target group, based on its ability to act collectively and exert power, and on design decisions that insulate intermediaries, to a greater or lesser degree, from target influence (Maggetti et al. 2017).

In addition to dominating existing intermediaries, targets frequently establish friendly intermediaries (e.g., professional or industry associations), with interests similar to their own, creating channels for capture. These intermediaries may be sufficiently responsive to regulatory intent to avoid stricter regulation. Alternatively, targets may bring in new intermediaries with the aim of influencing regulators directly (as when industry groups hire supposedly independent, expert organizations to advise regulators).

Multiple intermediaries can facilitate capture, especially if they have conflicting interests (e.g., alternative certification bodies that compete for business, a common feature of private standards schemes), and the target need capture only one of them (e.g., if the target may decide which certification body to employ). More broadly, if different intermediaries adopt divergent interpretations of a rule, targets may claim that compliance is too costly, or even impossible. Conversely, capture becomes more difficult if it requires capturing both the regulator and the intermediary. To the extent the regulator and intermediary monitor one another, capture may become very difficult for the target.

Finally, the ease and locus of capture may be affected by design rules. In particular, if the target pays for the intermediary's services - such as factory audits or financial instrument ratings - then the intermediary may be overly responsive to the target’s needs, especially if targets can engage in “intermediary shopping” (van der Heijden 2017), threatening to choose alternative intermediaries. This risk may be attenuated by professional or reputational considerations (as for accountants), or by institutional devices such as rotation or accreditation. 


\subsection{Capture of Regulator by the Intermediary}

Intermediaries too may capture a regulator. The initial demand for regulation frequently emerges from beneficiaries and other interest groups; erstwhile intermediaries often participate in these lobbying efforts. Intermediaries play similar roles in the dynamic regulatory process, providing feedback to regulators and recommending modifications in rules or policies. Intermediaries often have unusual influence in these settings: their expertise, informational advantages and experience put them in a better position than the regulator in terms of understanding needed modifications. In such cases, intermediaries become the leaders in regulation, with the ostensible rule-makers following them.

Intermediaries' goals are not necessarily noble or in the public interest. For example, accountants, auditors, credit ratings agencies, standards bodies, lawyers and other potential intermediaries may press for regulations that would increase demand for their services and products (and oppose those that would lessen it), while couching their advice in terms of their ability to strengthen interpretation, monitoring and enforcement. Intermediaries also press for rules that play to their organizational strengths and reduce their costs. For example, inspection firms prefer "desk audits” over "field audits," because they are less costly and can be performed more consistently; they therefore urge regulators to adopt rules or compliance indicators that are "auditable” in terms of documents or easily observed outputs, not on-theground impacts (Galland 2017). Intermediaries may also informally interpret rules to make them more amenable (Bartley 2016).

\subsection{Capture of the Intermediary by the Regulator}

A fourth type of capture is domination of an intermediary by the regulator. Such domination may be beneficial to the public interest if it prevents slippage between regulatory intent and practice due to the divergent goals of the intermediary, or if it prevents capture by 
powerful targets (Maggetti et al. 2017). But it may instead be antithetical to the public interest. For example, a regulator may introduce an intermediary to create the illusion of action or to distract attention from its own inadequacies. ${ }^{8}$

Even short of that, intermediation is often more than mere agency: it is also an assurance mechanism designed to create greater trust between target and regulator. The intermediary provides assurance through means such as adherence to professional norms and commitments, or institutionalized neutrality. In these settings, regulator domination of the intermediary is problematic. First, a captured intermediary may not (be allowed to) perform the desired regulatory functions. It may be unable to follow professional norms or act in a neutral fashion; it may even resist participation in the regulatory system to avoid regulator interference or takeover. Second, without assurance or trust building, the target may resist the regulation and avoid complying with it, perceiving the system to be biased against it. In short, regulator domination may undermine the very purpose of using an intermediary.

\section{Conclusion}

Focusing attention on intermediaries expands the scope of regulatory analysis beyond regulators and their targets to include other key agents in the regulatory process, whether that process is governmental or private, domestic or transnational. This analytical move allows us to capture and analyze changes in the nature of regulation that are often expressed in terms of the shift from government to governance, the rise of transnational actors and institutions, the growing importance of certification procedures, or the move towards process- or performance-based regulation.

The RIT model and its extensions emphasize that regulation often operates indirectly, through a variety of formal, informal and tacit relationships, involving complex 
configurations of regulatory actors. The model highlights how regulators and targets can expand their capacities for regulation in the public interest by engaging intermediaries in rule development, implementation, monitoring, trust-building, enforcement, and ex post assessment. But analysis under the model also allows us to investigate how intermediaries in regulatory systems pursue their private interests, and how other regulatory actors - from targets to beneficiaries - utilize intermediaries to pursue their own private interests, through capture, intermediary-shopping and other strategies. As regulatory governance evolves, then, both positive and normative analysis will increasingly require an understanding of the diverse roles of regulatory intermediaries. 


\section{References}

Abbott, Kenneth W., and Duncan, Snidal. 2000. Hard and soft law in international governance. International Organization 54(3): 421.

Abbott, Kenneth W., and Duncan, Snidal. 2009. Strengthening international regulation through transnational new governance: Overcoming the orchestration deficit. Vanderbilt Journal of Transnational Law 42: 1-80.

Abbott, Kenneth W., and Duncan, Snidal. 2010. International regulation without international government: Improving IO performance through orchestration. Review of International Organizations 5: 315.

Abbott, Kenneth W., Philipp Genschel, Duncan Snidal, and Bernhard, Zangl (eds.). 2015. International organizations as orchestrators. Cambridge University Press.

Auld Graeme and Stefan Renckens. 2017. Rule-making feedbacks through intermediation and evaluation in transnational private governance The Annals of the American Academy of Political and Social Science Vol. 670.

Ayres, Ian, and John Braithwaite. 1992. Responsive regulation: Transcending the deregulation debate. Oxford University Press.

Bartley, Tim. 2011. Certification as a mode of social regulation. In Handbook on the politics of regulation, ed. David Levi-Faur, 441-452. Edward Elgar, Northampton, MA.

Bartley, Tim. 2016. A substantivist-political theory of transnational private regulation. Paper prepared for conference on transnational business governance interactions, Toronto, May 2016.

Berman, Paul S. 2012. Global legal pluralism: A jurisprudence of law beyond borders. Cambridge University Press. 
Bernstein, Marver H. 1955. Regulating business by independent commission. Princeton University Press.

Bernstein, Steven, and Benjamin Cashore. 2007. Can non-state global governance be legitimate? An analytical framework. Regulation \& Governance 1(4): 347-371.

Black, Julia. 2003. Enrolling actors in regulatory systems: Examples from UK financial services regulation. Public Law (1): 63-91.

Black, Julia. 2008. Constructing and contesting legitimacy and accountability in polycentric regulatory regimes. Regulation \& Governance 2(2): 137-164.

Blauberger, M. and Rittberger, B., 2015. Conceptualizing and theorizing EU regulatory networks. Regulation \& Governance 9(4): 367-376.

Braithwaite, John. 2008. Regulatory capitalism: How it works, ideas for making it work better. Edward Elgar Publishing.

Büthe, Tim. 2010. Private regulation in the global economy: A (P)review. Business and Politics 12(3): 1-38.

Carpenter, Daniel, and David A. Moss (eds.). 2013. Preventing regulatory capture: Special interest influence and how to limit it. Cambridge University Press.

Coglianese, Cary, and David Lazer. 2003. Management-based regulation: Prescribing private management to achieve public goals. Law \& Society Review 37(4): 691-730.

Czarniawska-Joerges, B., and Sevón, G (eds.). 1996. Translating organizational change. Walter de Gruyter Press

De Silva, Nicole. 2017. Chains of Intermediaries in Regulatory Governance: The International Criminal Court's Use of NGOs in Regulating International Crimes. The Annals of the American Academy of Political and Social Science Vol. 670. 
DiMaggio, Paul J. and Walter W. Powell (eds.). 1991. The new institutionalism in organizational analysis. University of Chicago Press.

Fransen, L. and Conzelmann, T. 2015. Fragmented or cohesive transnational private regulation of sustainability standards? A comparative study. Regulation \& Governance 9(3): 259-275.

Galland, Jean-Pierre. 2017. Big third-party certifiers and the construction of transnational regulation. The Annals of the American Academy of Political and Social Science Vol. 670.

Gereffi, Gary, Roni Garcia-Johnson and Erika Sasser. 2001. The NGO-industrial complex. Foreign Policy 125 (Jul-Aug): 56-65.

Gilad, Sharon. 2010. It runs in the family: Meta-regulation and its siblings. Regulation \& Governance 4(4): 485-506.

Guardiancich, I. and Guidi, M., 2016. Formal independence of regulatory agencies and Varieties of Capitalism: A case of institutional complementarity? Regulation \& Governance 10(3): 211-229.

Kostka, G., 2016. Command without control: The case of China's environmental target system. Regulation \& Governance Vol 10(1):58-74.

Hall, Peter A., and Rosemary C. Taylor. 1996. Political science and the three new institutionalisms. Political studies 44(5): 936-957.

Havinga, Tetty and Paul Verbruggen. 2017. Understanding complex governance relationships in food safety regulation: The RIT model as theoretical lens. The Annals of the American Academy of Political and Social Science Vol. 670. 
Hood, Christopher, Henry Rothstein and Robert Baldwin. 2001. The government of risk: Understanding risk regulation regimes. Oxford University Press.

Jordana, Jacint. 2017. Transgovernmental networks as regulatory intermediaries: horizontal collaboration and the realities of soft power. The Annals of the American Academy of Political and Social Science Vol. 670.

Koenig-Archibugi, Mathias, and Kate Macdonald. 2013. Accountability-by-proxy in transnational non-state governance. Governance 26: 499-522.

Koenig-Archibugi, Mathias and Kate Macdonald. 2017. The role of beneficiaries in transnational regulatory processes, The Annals of the American Academy of Political and Social Science Vol. 670.

Kraakman, Reinier H. 1986. Gatekeepers: the anatomy of a third-party enforcement strategy. Journal of Law Economics \& Organization 2(1): 53-104.

Kruck A. 2017. Asymmetry in empowering and dis-empowering private intermediaries: The case of credit rating agencies, The Annals of the American Academy of Political and Social Science Vol. 670.

Levi-Faur, David. 2005. The global diffusion of regulatory capitalism. The Annals of the American Academy of Political and Social Science 598(1): 12-32.

Levi-Faur, David. 2011a. Regulation and regulatory governance. In Handbook on the politics of regulation, ed. David Levi-Faur, 3-21. Cheltenham: Edward Elgar.

Levi-Faur, David. 2011b. Regulatory networks and regulatory agencification: Toward a single European regulatory space. Journal of European Public Policy 18(6): 810-829.

Levi-Faur, David and Shana Starobin. 2014. Transnational politics and policy: From two-way to three-way interactions. Jerusalem Papers in Regulation and Governance No. 62. 
Loconto, Allison, and Lawrence Busch. 2010. Standards, techno-economic networks, and playing fields: Performing the global market economy. Review of International Political Economy 17(3): 36-507.

Loconto A.M. 2017. Models of assurance: Diversity and standardization of modes of intermediation, The Annals of the American Academy of Political and Social Science Vol. 670.

Lytton, Timothy D. 2017. The taming of the stew: Regulatory intermediaries in food safety governance The Annals of the American Academy of Political and Social Science Vol. 670.

Maggetti, M., Ewert C. and Trein P. 2017. Not quite the same: regulatory intermediaries in the governance of pharmaceutical and medical devices, The Annals of the American Academy of Political and Social Science Vol. 670.

Marx, Axel and Jan Wouters. 2017. Rule intermediaries in global labor governance,

The Annals of the American Academy of Political and Social Science Vol. 670.

Mattli, Walter and Jack Seddon. 2015. Orchestration along the Pareto frontier: Winners and losers. In International Organizations as Orchestrators eds. Kenneth W. Abbott, Philipp Genschel, Duncan Snidal, and Bernhard, Zangl, 315-348. Cambridge: Cambridge University Press.

Meidinger, Errol. 2003. Forest certification as a global civil society regulatory institution. In Social and political dimensions of forest certification, eds. E. Meidinger, C. Elliott and G. Oesten, 265-289. Forstbuch, Remagen-Oberwinter, Germany.

Nadvi, Khalid. 2008. Global standards, global governance and the organization of global value chains. Journal of Economic Geography 8(3): 323-343. 
Nadvi, Khalid and G. Raj-Reichert. 2015. Governing health and safety at lower tiers of the computer industry global value chain. Regulation \& Governance 9(3): 243-258.

North, Douglass C. 1990. Institutions, institutional change and economic performance. Cambridge University Press.

O'Rourke, Dara. 2003. Outsourcing regulation: Analyzing nongovernmental systems of labor standards and monitoring. Policy Studies Journal 31(1): 1-29.

Partnoy, Frank. 2007. How and why credit rating agencies are not like other gatekeepers. In Financial gatekeepers: Can they protect investors?, eds. Y. Fuchita and Robert E. Litan, 59-100. Brookings Institution Press.

Pegram Tom. 2017. Regulatory stewardship and intermediation: Comparative lessons from human rights governance. The Annals of the American Academy of Political and Social Science Vol. 670.

Potoski, Matthew and Aseem Prakash. 2011. Voluntary programs, compliance and the regulation dilemma. In Handbook on the Politics of Regulation, ed. David Levi-Faur, 84-95. Northampton, MA: Edward Elgar.

Scott, Colin. 2001. Analyzing regulatory space: Fragmented resources and institutional design. Public Law: 283-305.

Scott, Colin. 2004. Regulation in the age of governance: the rise of the post-regulatory state. In The politics of regulation: Institutions and regulatory reforms for the age of governance, eds. Jordana, Jacint and Levi-Faur, David, 145-174. Cheltenham: Edward Elgar Publishing.

Selznick, Philip. 1949. TVA and the grass roots. Berkeley: University of California Press. 
Selznick, Philip. 1985. Focusing Organizational Research on Regulation. In Regulatory Policy and Social Sciences, ed. R.G. Noll, 363-67. Berkeley and Los Angeles, University of California Press.

Shearing, Clifford D., and Philip C. Stenning. 1987. Say “cheese!”: The Disney order that is not so Mickey Mouse. In Private policing, eds. Clifford D. Shearing and Philip C. Stenning, 317-232. London: Sage.

Sinclair, Timothy J. 2005. The new masters of capital. Cornell University Press.

Starobin, Shana, and Erika Weinthal. 2010. The search for credible information in social and environmental global governance: The kosher label. Business and Politics 12(3) 1-35.

Stigler, George. 1971. The theory of economic regulation. Bell Journal of Economics and Management Science 2(3): 3-21.

Streeck, Wolfgang, and Kathleen A. Thelen. 2005. Beyond continuity: Institutional change in advanced political economies. Oxford University Press.

Toffel, M.W., Short, J.L. and Ouellet, M., 2015. Codes in context: How states, markets, and civil society shape adherence to global labor standards. Regulation \& Governance 9(3): 205-223.

Van der, Heijden J. 2017. Brighter and darker sides of intermediation: Target-oriented and self-interested intermediaries in the regulatory governance of buildings. The Annals of the American Academy of Political and Social Science Vol. 670.

Van der, Heijden J. 2015. Correlates of rigorous and credible transnational governance: A cross-sectoral analysis of best practice compliance in eco-labeling. Regulation \& Governance 9(3): 276-293.

Vogel, David. 2008. Private global business regulation. Annual Review of Political Science 11(1): 261-282. 
Vogel, David. 2010. The private regulation of global corporate conduct. Achievements and limitations. Business and Society 49(1): 68-87. 
${ }^{1}$ Coupled with variation in regulators and targets, this allows for many varieties of threeparty regulatory governance. Levi-Faur 2011a: 9.

${ }^{2}$ Leading definitions of "regulation” assume it is an activity of state agencies, Selznick 1985:363.

3 Abbott, Genschel, Snidal and Zangl 2015, 4, define orchestration as a process in which a regulator or other governor "enlists and supports intermediary actors to address target actors in pursuit of [its] governance goals.”

${ }^{4}$ We adapt these from Abbott and Snidal (2009). These are not the only relevant capacities intermediaries might have, but they include many of the most important ones.

${ }^{5}$ These functions correspond roughly to the information-gathering and behavior modification elements of regulation. Hood, Rothstein and Baldwin 2001.

${ }^{6}$ These examples take a broader view of "regulation” than some discussions, which limit it to actions taken by agencies, not by legislatures or courts. Levi-Faur 2011a.

${ }^{7}$ A regulation may indirectly constrain beneficiaries even when they are not its direct targets (Koenig-Archibugi and Macdonald 2017).

${ }^{8}$ We thank Jeroen van der Heijden for suggesting this point. 